\title{
Escala Multidimensional de Atitudes face a Lésbicas e a Gays: Construção e Validação Preliminar ${ }^{1}$
}

\author{
Jorge Gato ${ }^{2}$ \\ Anne Marie Fontaine \\ Nuno Santos Carneiro \\ Universidade do Porto, Porto, Portugal
}

\begin{abstract}
Resumo: O preconceito contra as pessoas não heterossexuais persiste e atualmente assume diversas formas. Este estudo teve por objetivo apresentar o processo de construção e validação de um instrumento multidimensional de avaliação de atitudes face a lésbicas e a gays. Partindo de uma revisão teórica sobre diversos aspectos do preconceito anti-homossexual, foram definidos três tipos de atitudes negativas. Selecionou-se, em seguida, um conjunto de escalas pré-existentes, tendo os seus itens sido categorizados de acordo com as atitudes previstas. Análises fatoriais exploratórias revelaram uma escala composta por três dimensões atitudinais negativas, duas de caráter mais tradicional (Rejeição da proximidade e Homopatologização) e uma de caráter mais atual (Heterossexismo moderno), assim como por uma atitude positiva (Suporte). Todas as dimensões apresentaram uma boa consistência interna. Provas adicionais da validade de constructo do instrumento foram obtidas através de um estudo diferencial, em função do sexo dos participantes e do seu contato interpessoal com lésbicas e gays.
\end{abstract}

Palavras-chave: Orientação Sexual, Homossexualidade, Preconceito, Atitudes Sexuais.

\section{Multidimensional Scale of Attitudes Toward Lesbians and Gay Men: Construction and Preliminary Validation}

\begin{abstract}
Prejudice against non-heterosexual individuals persists and currently assumes various forms. This study describes the process of developing and validating a multidimensional instrument to assess attitudes toward lesbians and gays. Three types of negative attitudes were defined based on a literature review of the various aspects of antigay prejudice. Existing scales were selected and their items were categorized according to expected attitudes. Factorial exploratory analysis revealed a scale composed of three negative attitudinal dimensions: two with a more traditional nature (Rejection of proximity and Pathologization of homosexuality) and a more contemporary one (Modern heterosexism), as well as a positive dimension (Support). All dimensions showed good internal consistency. Additional evidence of the instrument's construct validity was obtained through a differential study, based on the participants' gender and their interpersonal contact with lesbians and gay men.
\end{abstract}

Keywords: Sexual Orientation, Homosexuality, Prejudice, Sexual Attitudes.

\section{Escala Multidimensional de Actitudes Hacia Lesbianas y Gays: Construcción y Validación Preliminar}

\begin{abstract}
Resumen: El prejuicio contra las personas no heterosexuales persiste, asumiendo diversas formas hoy día. Se presenta en este trabajo el proceso de construcción y validación de un instrumento multidimensional de evaluación de las actitudes hacia las lesbianas y los gays. Partiendo de una revisión teórica sobre diversos aspectos del prejuicio, fueron definidos tres tipos de actitudes negativas. Posteriormente fueron seleccionadas escalas de evaluación pre-existentes, siendo sus ítems categorizados de acuerdo con las actitudes propuestas. Análisis factoriales exploratorias revelaron una escala compuesta por tres dimensiones negativas, dos de carácter más tradicional (Rechazo de aproximación y Homopatologización) y una de carácter más actual (Heterosexismo moderno), así como por una actitud positiva (Soporte). Todas las dimensiones presentaron consistencia interna adecuada. Pruebas adicionales de validez de constructo fueron obtenidas a través de un estudio diferencial, en función del sexo de los participantes y de su contacto interpersonal con lesbianas y gays.
\end{abstract}

Palabras clave: Conducta Sexual, Homosexualidad, Prejuicio, Actitudes Sexuales.

A crescente visibilidade e maior aceitação social das pessoas lésbicas e gays (Andersen \& Fetner, 2008; Carneiro \& Menezes, 2007; Costa, Pereira, Oliveira, \& Nogueira,

${ }^{1}$ Este artigo é fruto de pesquisa financiada por bolsa de doutoramento atribuída ao primeiro autor pela Fundação para a Ciência e Tecnologia (SFRH/BD/41752/2007).

${ }^{2}$ Endereço para correspondência

Jorge Gato. Faculdade de Psicologia e de Ciências da Educação da Universidade do Porto. Rua Dr. Manuel Pereira da Silva. 4.200-392. Porto, Portugal.E-mail: jorgegato@fpce.up.pt
2010) poderá fazer pensar que o preconceito e a discriminação em razão da orientação sexual já não constituem um problema. No entanto, como salientam Nogueira e Oliveira (2010), "se (...) a adopção de uma identidade gay ou lésbica é considerada uma orientação viável e saudável, por outro lado, existem ainda preconceitos e desinformação persistente sobre a homossexualidade com diferentes resultados e consequências" (p. 10). Por exemplo, nos EUA esta população permanece um dos principais grupos alvo de crimes de ódio e 
perseguição (Herek, 2009). A discriminação de que lésbicas e gays são vítimas é também patente nas taxas relativamente altas de suicídio e tentativas de suicídio em adolescentes e adultos não heterossexuais (Haas et al., 2011; Marshal et al., 2011). No que diz respeito a Portugal, apesar de algumas mudanças no sistema legal que visaram diminuir a discriminação baseada na orientação sexual (por exemplo, acesso ao casamento civil por casais do mesmo sexo; Lei n. ${ }^{\circ}$, de 31 maio de 2010), diversos inquéritos sociais indicam que os portugueses apresentam atitudes negativas face a lésbicas e a gays, especialmente quando se efetuam comparações com os outros países europeus (Comissão Europeia, 2009; European Commission, 2008). O estudo e a avaliação deste tipo de preconceito continuam, assim, a justificar-se.

As primeiras conceitualizações e instrumentos de avaliação do preconceito anti-homossexual pretenderam dar conta do seu caráter fóbico e sexista (Herek, 1988; Hudson \& Ricketts, 1980; Kite \& Deaux, 1986; Wright, Adams, \& Bernat, 1999). No entanto, tal como sucedeu relativamente a outros grupos discriminados, verificou-se que o preconceito contra lésbicas e gays adotou um caráter mais dissimulado. Nesta medida, novas teorias e instrumentos de avaliação surgiram (Morrison, Kenny, \& Harrington, 2005; Morrison \& Morrison, 2002; Park, 2001; Raja \& Stokes, 1998) (para uma revisão atualizada das abordagens psicológicas do preconceito contra pessoas não heterossexuais, sugere-se a consulta de Gato, Carneiro, \& Fontaine, 2011). Existem, assim, atualmente, diversos tipos de atitudes negativas face a lésbicas e a gays, desde as mais tradicionais até às mais modernas. Dada a inexistência de instrumentos originais em língua portuguesa, que avaliem simultaneamente estas atitudes, foi objetivo deste trabalho construir um instrumento que desse conta da complexidade das atitudes face a lésbicas e a gays, que se podem observar hoje em dia.

\section{A Condenação Moral e a Patologização da Homossexualidade}

São ainda visíveis diversas manifestações de condenação moral e patologização da homossexualidade. Até recentemente, o Instituto Português de Sangue excluía explicitamente os homossexuais masculinos da doação voluntária de sangue, deliberação justificada com a alegação de que os gays são sexualmente "mais promíscuos" do que os heterossexuais (Carneiro, 2006; "Recusa de Dádivas", 2009). Em 1999 a Classificação Nacional de Deficiências integrou a "homossexualidade", designando-a como "deficiência da função heterossexual" (Carneiro). Apesar de desde 1973, a homossexualidade não constar da lista de doenças mentais da Associação Americana de Psiquiatria, 36 anos mais tarde o presidente do Colégio de Psiquiatria da Ordem dos Médicos Portugueses ainda distinguia entre homossexualidade primária (adquirida biologicamente) e secundária (adquirida socialmente), declarando que a última pode ser objeto de tratamento psiquiátrico (Sanches, 2009). Um instrumento de avaliação do preconceito contra as pessoas homossexuais estará assim incompleto se não der conta da condenação moral e patologização da homossexualidade, ainda patente na sociedade contemporânea.

\section{Preconceito Tradicional versus Preconceito Moderno}

Além da avaliação do preconceito na sua forma mais clássica, isto é, da aversão emocional/rejeição da proximidade/evitamento relativamente aos membros do exogrupo (Allport, 1954/1997), devem também ter-se em atenção as suas expressões mais modernas. Efetivamente, as transformações nas atitudes face a lésbicas e a gays encontram um paralelo, quer no domínio dos novos preconceitos raciais e étnicos (racismo aversivo - Gaertner \& Dovidio, 2000; racismo moderno - McConahay, 1986; racismo sutil - Meertens \& Pettigrew, 1999), quer no domínio do preconceito de gênero contemporâneo (sexismo ambivalente - Glick \& Fiske, 2001; sexismo moderno - Swim, Aikin, Hall, \& Hunter, 1995; neo-sexismo - Tougas, Brown, Beaton, \& Joly, 1995). Globalmente, estas pesquisas têm salientado o caráter mais dissimulado do preconceito e a sua manutenção em sociedades nas quais as práticas discriminatórias são proibidas e onde as pessoas preconceituosas são mal vistas (Gato et al., 2011). Algumas destas conceitualizações foram utilizadas para explicar as modificações que também se observam na expressão do preconceito contra as pessoas não heterossexuais.

Diversos estudos (Quiles del Castillo, Betancor Rodríguez, Rodríguez Torres, Rodríguez Pérez, \& Coello Martel, 2003; Lacerda, Pereira, \& Camino, 2002; Marinho, Marques, Almeida, Menezes, \& Guerra, 2004; Pereira, Monteiro, \& Camino, 2009) aplicaram a teoria do preconceito racial flagrante versus sutil (Meertens \& Pettigrew, 1999; Pettigrew \& Meertens, 1995), ao preconceito contra lésbicas e gays. O preconceito racial flagrante corresponde ao preconceito tradicional e é caracterizado como quente, próximo e direto. É constituído por dois componentes: (a) percepção de que o exogrupo é uma ameaça, (b) rejeição de intimidade com os membros do exogrupo. O preconceito racial sutil é descrito como mais frio, distante e indireto. Consta de três fatores: (a) defesa de valores tradicionais/percepção de que o exogrupo não adere aos valores do trabalho e do sucesso, (b) acentuação das diferenças culturais, (c) negação de emoções positivas em relação ao exogrupo. Aplicando este modelo ao preconceito contra lésbicas e gays, Lacerda et al. e Pereira et al. utilizaram como indicador de preconceito flagrante, $\mathrm{o}$ componente rejeição da intimidade e de preconceito sutil, a negação de emoções positivas/expressão de emoções negativas. Por sua vez, Quiles del Castillo et al. e Marinho et al. verificaram uma distinção entre "homofobia flagrante" e "sutil" (nomenclatura utilizada pelos últimos autores).

Utilizando o racismo moderno (McConahay, 1986) e o neo-sexismo (Tougas et al.), como modelos inspiradores, 
Morrison e Morrison (2002) propuseram o conceito de homonegatividade moderna. Este baseia-se em crenças como: (a) as lésbicas e os gays exigem mudanças sociais desnecessárias, (b) o preconceito e a discriminação são um fenómeno do passado, (c) as lésbicas e os gays colocam demasiada ênfase na sua sexualidade e, ao fazê-lo, são responsáveis pela sua marginalização.

Contudo, as manifestações modernas de preconceito contra as pessoas não heterossexuais têm especificidades que as distinguem das formas contemporâneas de preconceito racial/étnico ou de sexismo (Massey, 2009). Em primeiro lugar, a população LGBT não está tão "protegida" pela norma social que impede a expressão de formas mais hostis de preconceito, como outros grupos aos quais é atribuído um estatuto inferior (Herek, 2007; Pereira et al., 2009). Por outras palavras, o preconceito contra as pessoas não heterossexuais é socialmente mais aceito do que o preconceito étnico ou o sexismo.

Em segundo lugar, a aplicação de teorias que explicam as manifestações contemporâneas de racismo ao preconceito sexual é problemática, uma vez que as ideologias que lhes estão subjacentes não são necessariamente as mesmas. De acordo com Hegarty (2006), mais do que receio da discriminação positiva, de competição econômica ou de diferenças culturais inconciliáveis, patentes no racismo moderno, o preconceito contra lésbicas e gays radica no desconforto com a sua crescente visibilidade e no questionamento que algumas destas pessoas fazem de valores e instituições tradicionalmente associados à heterossexualidade (por exemplo, o casamento e a parentalidade). A este propósito, Biernat, Vescio e Theno (1996) demonstraram que os valores relativos à ética protestante e ao igualitarismo aumentavam a probabilidade de usar a raça como uma base para avaliação do exogrupo, mas não a orientação sexual.

Pelo fato de homossexuais e heterossexuais partilharem geralmente a mesma cultura, a utilização de modelos sobre o preconceito racial para a avaliação do preconceito anti-homosexual pode revelar-se particularmente inadequada. Por exemplo, o item original de Pettigrew e Meertens (1995, tradução nossa), pertencente à subescala de rejeição da intimidade, da escala de preconceito tradicional, "Seria capaz de ter relações sexuais com uma pessoa das Antilhas" foi transformado por Quiles del Castillo et al. (2003, tradução nossa) em "Se se proporcionasse, e em determinadas circunstâncias, eu poderia sentir vontade de ter uma relação sexual com alguém do mesmo sexo". Ora, a discordância relativamente a cada um destes itens não é equivalente, dadas as ideologias que lhe subjazem. Assim, no caso da orientação sexual, o que está em jogo diz respeito, sobretudo, à influência do heterossexismo, enquanto ideologia que valoriza a heterossexualidade como mais natural que e/ou superior à homossexualidade, na leitura do que está a ser perguntado (Morin, 1977).

Em terceiro lugar, como acentuou Herek (2007), ao contrário da etnia/raça ou do gênero, a orientação sexual de uma pessoa não é necessariamente visível. A este propósito, Hegarty (2006) chamou a atenção para o fato de alguns estudos experimentais (Moreno \& Bodenhausen, 2001) terem sugerido que, em contextos sociais igualitários, não são as identidades lésbicas e gays que desencadeiam automaticamente preconceito, mas sim a visibilidade destas identidades. Por exemplo, Morrison e Morrison (2002) verificaram que sujeitos com pontuações mais elevadas na sua escala de homonegatividade moderna, evitavam ver um filme num laboratório com um homem que tivesse vestido uma $t$-shirt que o identificasse como gay, quando havia uma outra razão plausível, para além da sua identidade sexual, para ver o filme noutra sala. Segundo Hegarty, esta experiência é bem elucidativa acerca dos custos sociais associados à expressão e visibilidade de uma identidade gay/lésbica. Assim, não serão as identidades, mas as manifestações explícitas destas identidades que motivam o tratamento derrogatório, principalmente quando questionam a normatividade da heterossexualidade no espaço público.

Como se procurou demonstrar, a transposição direta dos modelos explicativos do preconceito racial e de gênero modernos para a avaliação do preconceito contemporâneo contra lésbicas e gays não é isenta de problemas. Assim, uma avaliação específica e completa do preconceito anti-homossexual moderno deverá abarcar os seguintes posicionamentos: (a) os já contemplados no racismo/homonegatividade modernos, de que não há discriminação e de que a luta por direitos iguais não se justifica; (b) os que dizem respeito ao desempenho de papéis tradicionalmente associados à heterossexualidade, como o casamento e a parentalidade; (c) os que se relacionam com a visibilidade/expressão da identidade lésbica e gay.

Em síntese, diversas atitudes parecem coexistir, desde as mais tradicionais, até às mais modernas. Dentro das expressões mais tradicionais será importante avaliar dois tipos de atitudes: por um lado, a condenação moral e a patologização da homossexualidade; por outro lado, o preconceito tradicional clássico, isto é, a rejeição/evitamento da interação com lésbicas e gays em diversos contextos e papéis sociais, associados à manifestação de emoções negativas relativamente a esta população (Quiles del Castillo et al., 2003; Lacerda et al., 2002; Marinho et al., 2004; Pereira et al., 2009). No que diz respeito às manifestações contemporâneas de preconceito, além da atitude patente na homonegatividade moderna (Morrison et al., 2005; Morrison \& Morrison, 2002), é importante avaliar as atitudes, quer relativamente ao casamento entre pessoas do mesmo sexo e à parentalidade lésbica e gay, quer face à visibilidade ou expressão da identidade lésbica $\mathrm{e}$ gay (Hegarty, 2006; Herek, 2007).

\section{Influência do Sexo e do Contato Interpessoal nas Atitudes face a Lésbicas e a Gays}

O sexo é um dos preditores mais poderosos das atitudes face a lésbicas e a gays, sendo as atitudes dos homens mais 
homofóbicas do que as das mulheres. Efetivamente, numa meta-análise de 109 estudos acerca da relação entre sexo do participante e atitudes perante lésbicas e gays, Kite e Whitley (1996) confirmaram esta diferença, sendo este padrão também observável em amostras de estudantes universitários (Evans, 2001). Perante estas evidências, previu-se que a escala construída evidenciaria a influência do sexo dos participantes nos diferentes tipos de atitudes avaliadas. Foram, assim, testadas as diferenças entre os participantes do sexo masculino e feminino, esperando-se que os primeiros demonstrariam atitudes mais negativas do que as suas congêneres do sexo feminino.

No que diz respeito ao contato interpessoal, diversos são os estudos que têm confirmado que as pessoas que afirmam conhecer lésbicas e/ou gays expressam, geralmente, atitudes menos negativas relativamente a pessoas não heterossexuais do que aquelas que não têm qualquer contato (Bowen \& Bourgeois, 2001; Herek \& Capitanio, 1996; Iraklis, 2010; Lemm, 2006; Sakalli, 2002). Ter amigos homossexuais é, efetivamente, um fator que influencia a perspectiva que os europeus têm da existência de discriminação contra as minorias sexuais: $56 \%$ dos respondentes com amigos homossexuais afirmaram que a discriminação era dominante, diminuindo este valor para $48 \%$ no caso dos respondentes sem amigos homossexuais (European Commission, 2007). Tendo em consideração os estudos apresentados, esperavase que os participantes que não têm amigos homossexuais (lésbicas e/ou gays) apresentariam atitudes mais negativas do que aqueles que têm amigos homossexuais.

Este estudo teve por objetivo apresentar o processo de construção e validação de um instrumento que avalia simultaneamente três tipos de atitudes face a lésbicas e a gays, duas de caráter mais tradicional e uma de caráter mais moderno. A fim de recolher mais elementos em prol da validade de constructo do instrumento, foi também investigada a sua capacidade de diferenciação, no sentido esperado, das dimensões avaliadas em função do sexo e do contato interpessoal com lésbicas e gays.

\section{Método}

\section{Participantes}

Participaram no estudo 380 estudantes universitários portugueses (59\% do sexo feminino), provenientes de três cursos da Universidade e Instituto Politécnico do Porto, Portugal (Psicologia, Fisioterapia e Engenharia Mecânica), com idades compreendidas entre os 18 e os 53 anos $(M=21,53$; $D P=4,62$ ).

\section{Instrumentos}

Os intrumentos utilizados são descritos a seguir.

Questionário sociodemográfico: foram recolhidas informações relativamente ao sexo, idade e curso de frequência.
O contato interpessoal dos participantes com lésbicas e gays foi avaliado por meio da questão, "Tem amigas e/ou amigos homossexuais (lésbicas e/ou gays)?”.

Versão Preliminar da Escala de Atitudes face a Lésbicas e a gays. Este instrumento foi aplicado com o objetivo de obter um conjunto de itens que representassem adequadamente os domínios conceituais a avaliar, garantindo a validade de conteúdo do instrumento; selecionaram-se algumas escalas de atitudes perante a homossexualidade: Attitudes Toward Lesbian Women/Gay Men (Herek, 1988), Index of Homophobia (Hudson \& Ricketts, 1980), Homosexuality Attitude Scale (Kite \& Deaux, 1986), Modern Homonegativity Scale (Morrison et al., 2005), Heterosexism Scale (Park, 2001), Modern Homophobia Scale (Raja \& Stokes, 1998) e The Homophobia Scale (Wright et al., 1999). A tradução e a retroversão deste conjunto de itens foram asseguradas por dois especialistas em português e inglês.

Seis pessoas com formação em Psicologia classificaram os itens de acordo com as seguintes categorias: homopatologização, rejeição da proximidade e heterossexismo moderno (sendo-lhes facultada a definição destas categorias). Apenas os itens que apresentaram um índice de concordância interjuízes superior a $80 \%$ foram selecionados. Este processo finalizou-se com a reformulação de alguns itens e construção de outros de modo a abarcar o conjunto do campo conceitual, dando origem a uma primeira versão da Escala Multidimensional de Atitudes Face a Lésbicas e a Gays (EMAFLG). A validade facial desta primeira versão foi assegurada a partir de uma reflexão falada com um grupo de quatro jovens adultos portugueses. Foi utilizada uma escala de resposta tipo Likert de 1 (discordo completamente) a 6 (concordo completamente).

\section{Procedimento}

\section{Coleta de Dados}

Após permissão das respetivas instituições de ensino superior, os questionários foram coletivamente administrados no período disponibilizado para o efeito pelo primeiro autor do estudo assistido por duas estudantes de Mestrado em Psicologia.

\section{Análise dos Dados}

A versão preliminar do instrumento foi sujeita a uma Análise Fatorial em Componentes Principais. As diferenças nas atitudes em função do sexo e do contacto interpessoal com lésbicas e gays foram calculadas através do teste $\mathrm{t}$ de Student.

\section{Considerações Éticas}

A coleta de dados foi antecedida de Consentimento Livre e Esclarecido. Os participantes foram esclarecidos acerca 
da natureza voluntária da participação e do propósito do estudo, tendo sido também assegurados a confidencialidade e o anonimato das respostas.

\section{Resultados}

\section{Análises Fatoriais Exploratórias}

Antes de se proceder à Análise Fatorial Exploratória (AFE), analisou-se a dispersão dos itens pelas seis opções de resposta. Eliminaram-se três itens demasiado consensuais, com uma concentração superior a $70 \%$ na primeira opção da escala de resposta (discordo totalmente) e que correspondiam a afirmações fortemente negativas sobre as pessoas homossexuais (item $n^{\circ} 5$, "As pessoas homossexuais deviam ser separadas do resto da sociedade: habitações, empregos restritos etc."; item $\mathrm{n}^{\circ} 8$, "Mudaria o meu filho de turma se descobrisse que a sua professora ou o seu professor era homossexual; e item $\mathrm{n}^{\circ} 15$, "Se descobrisse que uma amiga minha ou um amigo meu era homossexual, acabaria com essa amizade"). A AFE foi realizada com 30 itens, 11 categorizados como pertencendo à dimensão rejeição da proximidade, seis à dimensão homopatologização e 13 à dimensão heterossexismo moderno (Tabela 1).

A adequabilidade da amostra à AFE (componentes principais) foi verificada através do índice de Kaiser-MeyerOlkin (KMO), cujo valor de 0,957 sugeriu que as variáveis estavam correlacionadas e a análise fatorial era fortemente recomendada. Sendo o objetivo do estudo obter constructos teoricamente significativos e correlacionados entre si, isto é, diferentes tipos de atitudes negativas face a lésbicas e a gays, utilizou-se um método de rotação oblíqua (Direct Oblimin). Uma vez que o número de dimensões hipotetizadas estava definido, foi utilizado um critério a priori para a extração dos fatores, isto é, foram extraídos três fatores. A solução obtida explicou $52,4 \%$ da variância total. O fator 1 foi saturado por 16 itens, cinco pertencentes à categoria homopatologização e 11 à rejeição da proximidade. Os sete itens que saturaram o fator 2 pertenciam à categoria heterossexismo moderno e relacionavam-se com a visibilidade e luta pela igualdade de direitos de lésbicas e gays. $\mathrm{O}$ fator 3 agregava sete itens pertencentes à categoria heterossexismo moderno, que diziam sobretudo respeito ao casamento e à parentalidade. Não sendo teoricamente interpretável à luz das categorias propostas e dado que a análise do scree plot sinalizou a existência de mais um fator, foram extraídos quatro fatores. Esta nova solução explicou $56,6 \%$ da variância total. No que diz respeito à organização fatorial dos itens, o fator 1 reuniu os itens pertencentes à categoria rejeição da proximidade; o fator 2 continuava a ser saturado pelos itens do heterossexismo moderno que se referiam à visibilidade e direitos das lésbicas e dos gays; o fator 3 reuniu itens da categoria heterossexismo moderno que se relacionavam, quer com as atitudes negativas relativamente à homoparentalidade e às relações conjugais entre pessoas do mesmo sexo, quer com algum desconforto com a expressão da identidade lésbica e gay; os itens da categoria homopatologização saturavam o fator 4 .

Tabela 1

Análise Fatorial em Componentes Principais da Versão Preliminar da EMAFLG

\begin{tabular}{|c|c|c|c|c|c|c|}
\hline Itens & & Fator 1 & Fator 2 & Fator 3 & Fator 4 & $\mathrm{~h}^{2}$ \\
\hline 28. Não me importaria de trabalhar com uma pessoa que fosse homossexual. ${ }^{a}$ & $\mathrm{RP}$ &,- 78 &, 08 &, 06 &,- 07 & ,70 \\
\hline $\begin{array}{l}\text { 21. Sentir-me-ia pouco à vontade se descobrisse que o meu médico ou a minha médica } \\
\text { não era heterossexual. }{ }^{\mathrm{d}}\end{array}$ & $\mathrm{RP}$ & ,72 &, 01 &,- 04 & 03 &, 51 \\
\hline 29. Os gays e as lésbicas enervam-me. ${ }^{\mathrm{d}}$ & $\mathrm{RP}$ & ,70 & 09 & ,32 & , 16 &, 52 \\
\hline $\begin{array}{l}\text { 12. Hesitaria em apoiar pessoas homossexuais com medo de ser confundido(a) com } \\
\text { elas. }^{\mathrm{d}}\end{array}$ & $\mathrm{RP}$ & ,69 & 15 & ,23 &,- 11 &, 52 \\
\hline 24. Não votaria num(a) candidato(a) homossexual nas eleições. ${ }^{c}$ & $\mathrm{RP}$ & ,68 &,- 10 & 02 & 14 & ,66 \\
\hline 23. Sinto que não se pode confiar numa pessoa que é homossexual. ${ }^{\mathrm{d}}$ & $\mathrm{RP}$ & ,66 &,- 11 &,- 24 & ,13 &, 51 \\
\hline $\begin{array}{l}\text { 18. Sentir-me-ia desconfortável se soubesse que o professor ou a professora de um } \\
\text { filho meu ou de uma filha minha era homossexual. }{ }^{\text {e }}\end{array}$ & $\mathrm{RP}$ & ,64 &,- 01 &,- 01 & 28 & ,66 \\
\hline 1. Para mim é igual se os meus amigos são heterossexuais ou homossexuais. ${ }^{d}$ & $\mathrm{RP}$ &,- 62 & 09 &,- 04 &,- 04 &, 50 \\
\hline $\begin{array}{l}\text { 31. Não me importo que uma empresa contrate uma figura pública abertamente } \\
\text { homossexual para fazer publicidade aos seus produtos. }^{\text {a }}\end{array}$ & $\mathrm{RP}$ &,- 60 &, 15 & ,08 &,- 10 &, 50 \\
\hline $\begin{array}{l}\text { 7. Se fosse pai ou mãe, poderia aceitar que o meu filho ou a minha filha fosse } \\
\text { homossexual. }{ }^{\text {. }}\end{array}$ & $\mathrm{RP}$ &,- 59 & 07 &,- 24 &,- 04 & ,62 \\
\hline $\begin{array}{l}\text { 16. É revoltante ver duas pessoas do mesmo sexo de mãos dadas ou a demonstrar o } \\
\text { seu afecto em público. }{ }^{\text {c }}\end{array}$ & $\mathrm{RP}$ & ,39 &,- 14 & ,29 & ,26 & ,64 \\
\hline $\begin{array}{l}\text { 14. As pessoas que assumem a sua homossexualidade devem ser admiradas pela sua } \\
\text { coragem. } \text {. }^{\text {. }}\end{array}$ & $\mathrm{HM}$ &, 13 & ,79 &,- 04 & ,06 &, 55 \\
\hline 17. As lésbicas e os gays ainda precisam de lutar por direitos iguais. ${ }^{\mathrm{f}}$ & $\mathrm{HM}$ &,- 01 & ,77 &, 05 &,- 11 & ,63 \\
\hline 27. Vejo o movimento gay como algo de positivo. ${ }^{c}$ & $\mathrm{HM}$ &,- 24 & ,69 &,- 14 &, 12 & ,72 \\
\hline
\end{tabular}


Tabela 1 (continuação)

\begin{tabular}{|c|c|c|c|c|c|c|}
\hline Itens & & Fator 1 & Fator 2 & Fator 3 & Fator 4 & $\mathrm{~h}^{2}$ \\
\hline 11. As organizações que promovem os direitos dos homossexuais são necessárias. ${ }^{d}$ & HM &,- 22 & ,66 &,- 16 &,- 06 & 69 \\
\hline $\begin{array}{l}\text { 9. Um programa escolar de educação sexual deveria referir-se a todas as orientações } \\
\text { sexuais. }^{d}\end{array}$ & $\mathrm{HM}$ &,- 07 &, 56 & ,06 &,- 25 & ,49 \\
\hline $\begin{array}{l}\text { 4. Os professores deveriam tentar reduzir o preconceito dos seus alunos relativamente } \\
\text { à homossexualidade. }^{\mathrm{a}}\end{array}$ & $\mathrm{HM}$ &,- 01 &, 51 &,- 04 &,- 36 &, 54 \\
\hline $\begin{array}{l}\text { 32. Acho bem que as pessoas homossexuais se tenham tornado mais visíveis na } \\
\text { sociedade. }^{d}\end{array}$ & $\mathrm{HM}$ &,- 35 &, 50 &,- 03 &,- 06 &, 59 \\
\hline $\begin{array}{l}\text { 30. Ser criado num lar homossexual é bastante diferente de ser criado num lar } \\
\text { heterossexual. }\end{array}$ & $\mathrm{HM}$ &,- 09 &, 10 & ,80 & ,22 & 63 \\
\hline 3. Acredito que os pais homossexuais são tão capazes como os pais heterossexuais. ${ }^{d}$ & $\mathrm{HM}$ & ,06 &, 24 &,- 57 &,- 19 &, 54 \\
\hline $\begin{array}{l}\text { 13. Os casais do mesmo sexo deveriam, tal como os casais heterossexuais, poder } \\
\text { adotar crianças. }{ }^{\text {b }}\end{array}$ & $\mathrm{HM}$ &,- 03 & ,30 &,- 56 &,- 16 & ,63 \\
\hline $\begin{array}{l}\text { 25. Quando ouço falar numa relação amorosa, parto do princípio que são duas pessoas } \\
\text { do sexo oposto. }{ }^{\text {d }}\end{array}$ & $\mathrm{HM}$ & ,09 &, 02 &, 50 &,- 04 & ,28 \\
\hline $\begin{array}{l}\text { 19. Celebrações como o "dia do orgulho gay" são ridículas porque assumem que a } \\
\text { orientação sexual deve constituir um motivo de orgulho. }{ }^{\text {f }}\end{array}$ & $\mathrm{HM}$ &, 10 &,- 28 & ,49 &,- 26 & ,44 \\
\hline $\begin{array}{l}\text { 33. A legalização do casamento entre pessoas do mesmo sexo irá abalar os princípios } \\
\text { fundamentais da sociedade. }{ }^{\mathrm{d}}\end{array}$ & $\mathrm{HM}$ &, 11 & 01 & ,47 & ,28 & ,43 \\
\hline 26. Os gays e as lésbicas deveriam parar de impingir o seu estilo de vida aos outros. ${ }^{f}$ & HM &, 24 &,- 19 & ,46 &,- 14 & ,45 \\
\hline $\begin{array}{l}\text { 22. As lésbicas e os gays deveriam submeter-se a terapia para mudar a sua orientação } \\
\text { sexual. }^{\text {a }}\end{array}$ & HP &, 15 &,- 09 &, 10 & ,70 & ,72 \\
\hline 2. A homossexualidade é uma perturbação psicológica. ${ }^{a}$ & HP &, 15 &,- 02 & ,20 & ,66 & 68 \\
\hline 20. Se realmente quisessem, as lésbicas e os gays poderiam ser heterossexuais. ${ }^{a}$ & HP & 09 &,- 11 &, 11 &, 56 & ,48 \\
\hline 6. A homossexualidade é uma forma inferior de sexualidade. ${ }^{b}$ & HP &, 25 &,- 01 &,- 01 &, 55 & ,49 \\
\hline $\begin{array}{l}\text { 10. A crescente aceitação da homossexualidade na nossa sociedade está a contribuir } \\
\text { para a deterioração dos valores morais. }{ }^{c}\end{array}$ & HP &, 24 &,- 13 &, 27 & ,47 & 69 \\
\hline \% de Variância Total Explicada & & 40,99 & 6,46 & 4,98 & 4,20 & \\
\hline Valores próprios & & 12,30 & 1,94 & 1,50 & 1,26 & \\
\hline Alpha de Cronbach & & ,91 &, 83 &, 79 &, 86 & \\
\hline
\end{tabular}

Nota. RP - Rejeição da proximidade. HM - Heterossexismo modern. HP - Homopatologização. ${ }^{a}$ Modern Homophobia Scale (Raja \& Stokes, 1998). ${ }^{\mathrm{b}}$ Attitudes Toward Lesbian Women/Gay Men (Herek, 1988). ${ }^{\mathrm{c}}$ Homosexuality Attitude Scale (Kite \& Deaux, 1986). ${ }^{\mathrm{d}}$ Heterosexism Scale (Park, 2001). ${ }^{\mathrm{e}}$ Index of Homophobia (Hudson \& Ricketts, 1980). ${ }^{\mathrm{f}}$ Modern Homonegativity Scale (Morrison et al., 2005).

Como se pode observar na Tabela 1 , todos os itens apresentaram saturações fatoriais iguais ou superiores a 0,45 . Os itens $n^{\circ} 4, n^{\circ} 16$ e $n^{\circ} 32$ saturaram mais do que um fator, pelo que foram eliminados. Os valores de comunalidade revelaram-se aceitáveis exceto no que se refere aos itens $n^{\circ} 19, n^{\circ}$ 25 e $\mathrm{n}^{\mathrm{o}} 33$.

A análise dos valores de alpha de Cronbach revelou uma boa consistência interna para as quatro dimensões (Tabela 1). Assim, optou-se por manter os itens com comunalidades mais baixas nos fatores a que pertenciam. Após supressão dos itens $n^{\circ} 4, n^{\circ} 16$ e $n^{\circ} 32$, foi realizada uma nova análise fatorial, com 27 itens, que confirmou a estrutura anterior e explicou $56,7 \%$ da variância total.

Dado que os itens que saturaram no fator 2 se referiam ao apoio dos direitos civis e admiração por lésbicas e gays, este fator foi denominado Suporte. Por serem consistentes com as dimensões teóricas previstas, os outros três fatores mantiveram os nomes. As atitudes negativas (Rejeição da proximidade, Heterossexismo moderno e Homopatologização) e a atitude positiva (Suporte) correlacionaram-se negativamente, de uma forma estatisticamente significativa. Adicionalmente, as duas atitudes negativas mais tradicionais
(Rejeição da proximidade e Homopatologização) apresentaram a correlação mais elevada (Tabela 2).

Tabela 2

Matriz de Correlações das Escalas da EMAFLG

\begin{tabular}{lccc}
\hline & 2. & 3. & 4. \\
\hline 1. Rejeição da intimidade &,$- 61^{*}$ &, $62 *$ &, $71^{*}$ \\
2. Suporte & &,$- 62 *$ &,$- 57^{*}$ \\
3. Heterossexismo moderno & & &, $60^{*}$ \\
4. Homopatologização & & & \\
\hline$* p<, 001$. & & &
\end{tabular}

\section{Estudo Diferencial}

No que diz respeito às diferenças em função do sexo, como se pode constatar na Tabela 3, os homens reportaram valores significativamente mais elevados do que as mulheres, nas escalas de Rejeição da proximidade, Heterossexismo moderno e Homopatologização, sucedendo o oposto na escala Suporte. 
Tabela 3

Diferenças em Função do Sexo

\begin{tabular}{|c|c|c|c|c|c|c|c|}
\hline \multirow{2}{*}{ Variável } & \multicolumn{2}{|c|}{ Mulheres } & \multicolumn{2}{|c|}{ Homens } & \multirow{2}{*}{$t$} & \multirow{2}{*}{ g.l. } & \multirow{2}{*}{$P$} \\
\hline & $M$ & $D P$ & $M$ & $D P$ & & & \\
\hline Rejeição da proximidade & 1,80 & 0,72 & 2,48 & 0,94 & $-7,46$ & 249,57 & $<, 001$ \\
\hline Suporte & 4,82 & 0,76 & 4,10 & 1,04 & 7,31 & 256,80 & $<, 001$ \\
\hline Heterossexismo moderno & 3,33 & 0,93 & 3,95 & 0,92 & $-6,23$ & 359 & $<, 001$ \\
\hline Homopatologização & 1,67 & 0,72 & 2,35 & 1,06 & $-6,75$ & 238,25 & $<, 001$ \\
\hline
\end{tabular}

Quanto às diferenças em função do contato interpessoal, verificou-se que $35 \%$ dos participantes responderam afirmativamente, $31 \%$ negativamente e $32 \%$ "não sei". Os participantes que afirmaram não saber se tinham amigas/ os lésbicas e/ou gays foram contabilizados como não tendo contato interpessoal com lésbicas e gays. Verificou-se o mesmo padrão de diferenças entre as médias das escalas
(Tabela 4), já observado para o sexo. Assim, os participantes que não tinham contato interpessoal com lésbicas e gays evidenciaram valores significativamente mais elevados do que os seus congêneres com contato interpessoal, nas escalas de Rejeição da proximidade, Heterossexismo moderno e Homopatologização, acontecendo o inverso na escala Suporte.

Tabela 4

Diferenças em Função do Contacto Interpessoal com Lésbicas e Gays

\begin{tabular}{|c|c|c|c|c|c|c|c|}
\hline \multirow{2}{*}{ Variável } & \multicolumn{2}{|c|}{ Sem contacto } & \multicolumn{2}{|c|}{ Com contacto } & \multirow{2}{*}{$t$} & \multirow{2}{*}{ g.l. } & \multirow{2}{*}{$P$} \\
\hline & $M$ & $D P$ & $M$ & $D P$ & & & \\
\hline Rejeição da proximidade & 2,27 & 0,90 & 1,71 & 0,73 & $-6,30$ & 311,60 & $<0,001$ \\
\hline Suporte & 4,40 & 0,96 & 4,77 & 0,91 & 3,59 & 366 & $<0,001$ \\
\hline Heterossexismo moderno & 3,76 & 0,96 & 3,23 & 0,89 & $-5,06$ & 353 & $<0,001$ \\
\hline Homopatologização & 2,07 & 0,97 & 1,67 & 0,74 & $-4,34$ & 320,64 & $<0,001$ \\
\hline
\end{tabular}

\section{Discussão}

Descreveu-se neste trabalho o processo de construção e validação preliminar de um instrumento de avaliação de diferentes tipos de atitudes face a lésbicas e a gays. A Escala Multidimensional de Atitudes Face a Lésbicas e a Gays (EMAFLG) é composta por três fatores negativos (Homopatologização, Rejeição da proximidade e Heterossexismo moderno) e por um fator positivo (Suporte).

A Homopatologização diz respeito a uma atitude tradicional de condenação moral e patologização da homossexualidade que ainda é possível observar actualmente (Carneiro, 2006; "Recusa de Dádivas", 2009; Sanches, 2009). A Rejeição da proximidade é uma manifestação clássica de preconceito que se relaciona com a rejeição/evitamento da convivência com lésbicas e gays em diversas circunstâncias sociais e com a manifestação de emoções negativas relativamente a esta população (Allport, 1954/1997; Lacerda et al., 2002; Marinho et al., 2004; Meertens \& Pettigrew, 1999; Pereira et al., 2009; Pettigrew \& Meertens, 1995; Quiles del Castillo et al., 2003).

O Heterossexismo moderno compreende itens que dizem respeito à homonegatividade moderna (Morrison et al., 2005; Morrison \& Morrison, 2002) e que são comuns a outros preconceitos contemporâneos (Gaertner \& Dovidio, 2000; Glick \& Fiske, 2001; McConahay, 1986; Swim et al., 1995; Tougas et al., 1995). Incluem-se ainda nesta subescala posicionamentos relativos ao casamento entre pessoas do mesmo sexo, à homoparentalidade e à visibilidade/expressão das identidades lésbica e gay (Biernat et al., 1996; Hegarty, 2006; Herek, 2007; Moreno \& Bodenhausen, 2001; Morin, 1997).

A previsão inicial de que o instrumento deveria evidenciar três tipos de atitudes negativas face a lésbicas e a gays confirmou-se apenas parcialmente. Se, por um lado, a AFE evidenciou os três tipos de atitudes negativas hipotetizados, por outro lado, emergiu um outro fator de caráter positivo. Este fator reuniu itens que pertenciam à categoria heterossexismo moderno, que questionam genericamente a necessidade de um movimento de luta pela igualdade de direitos de lésbicas e gays e a desejabilidade da visibilidade da orientação homossexual. Contrariamente ao previsto, estes itens não saturaram o fator Heterossexismo moderno, agrupandose numa dimensão autônoma. Efetivamente, o suporte dos direitos de lésbicas e gays faz hoje parte do leque de atitudes perante esta população. Assim, embora lésbicas e gays continuem a ser vítimas de preconceito e discriminação (Comissão Europeia, 2009; European Commission, 2008; Haas et al., 
2011; Herek, 2009; Marshal et al., 2011; Nogueira \& Oliveira, 2010), é também visível uma evolução nas atitudes face aos mesmos (Andersen \& Fetner, 2008; Carneiro \& Menezes, 2007; Costa et al., 2010). Não se pode também deixar de considerar que o fato de este estudo ter sido conduzido numa época de intenso debate político em Portugal, sobre o acesso ao casamento civil entre pessoas do mesmo sexo, possa ter contribuído para que o fator Suporte tenha emergido. Na sua conceitualização multidimensional das atitudes face a lésbicas e a gays, além de atitudes negativas, Massey (2009) também tinha identificado atitudes positivas, dizendo uma delas respeito à valorização das conquistas do movimento gay. Utilizando o instrumento proposto por Massey, Costa et al. verificaram que esta atitude positiva fazia parte do reportório das atitudes face a lésbicas e a gays de uma amostra portuguesa. Portanto, a existência deste tipo de atitude não contraria os pressupostos deste estudo. Antes pelo contrário, é indicador da complexidade e multiplicidade das atitudes contemporâneas face a lésbicas e a gays (Gato et al., 2011).

No que diz respeito à fiabilidade da escala, os fatores apresentam níveis elevados de consistência interna. Correlacionam-se também de forma significativa e no sentido esperado, destacando-se o fato das duas atitudes mais tradicionais apresentarem a correlação mais elevada. O estudo diferencial realizado forneceu também provas da validade de constructo do instrumento. Assim, consistentemente com a literatura revista (Bowen \& Bourgeois, 2001; European Commission, 2007; Evans, 2001; Herek \& Capitanio, 1996; Iraklis, 2010; Kite \& Whitley, 1996; Lemm 2006; Sakalli, 2002), as mulheres e os participantes que reportaram ter contato interpessoal com lésbicas e gays subscreveram menos as atitudes negativas e mais a atitude positiva, do que os homens e os participantes sem contato interpessoal com lésbicas e gays.

\section{Conclusões}

Os resultados deste estudo devem ser lidos tendo em conta algumas limitações metodológicas. Em primeiro lugar, foi utilizada uma amostra não representativa da população portuguesa. Dado que em Portugal menos de $10 \%$ da população completou um curso superior (Instituto Nacional de Estatística [INE], 2002), a amostra difere claramente da população geral.

Em segundo lugar, a orientação sexual dos participantes não era conhecida. Contudo, uma vez que as pessoas não heterossexuais detêm, com maior probabilidade, atitudes menos estereotipadas e hostis relativamente aos seus congêneres, a presença de participantes lésbicas e gays pode ter reduzido a amplitude das diferenças observadas nas atitudes em função do sexo e do contato interpessoal. Deve, no entanto, ser notado que esta limitação aumenta a probabilidade de ocorrência do erro de tipo-II, não invalidando os resultados.
Em terceiro lugar, o fato de se ter contabilizado os participantes que afirmaram não saber se tinham amigos não heterossexuais como não tendo contato interpessoal com esta população, pode também ser considerado uma limitação do estudo. A este respeito, salienta-se ainda que a relação entre o contato interpessoal e as atitudes é provavelmente de tipo recíproco. Por um lado, ter amigos não heterossexuais pode facilitar a desconstrução de estereótipos e diminuir o preconceito. Por outro lado, as pessoas que têm amigos gays e/ ou lésbicas poderão ser, à partida, mais abertas e disponíveis para estabelecer relacionamentos sociais independentemente da orientação sexual dos interlocutores. Os próprios gays e as próprias lésbicas poderão ter um papel ativo neste processo, revelando preferencialmente a sua orientação a pessoas que, à partida, percebem como menos preconceituosas.

Finalmente, a estrutura fatorial evidenciada carece de confirmação numa amostra diferente, pelo que no futuro se deverão realizar análises fatoriais confirmatórias do instrumento. A utilização da EMALFG noutros países de língua oficial Portuguesa deverá ser antecedida de adaptação ou reformulação semântica e as suas qualidades psicométricas deverão ser analisadas com recurso a análises de invariância (análises fatoriais confirmatórias multigrupo).

Considerando que a coexistência de diversos tipos de atitudes face a lésbicas e a gays pode ser melhor apreendida com instrumentos de caráter multidimensional, a EMAFLG é um instrumento com boas características psicométricas que poderá ser utilizado com esse propósito.

\section{Referências}

Allport, G. (1997). The nature of prejudice. Cambridge, MA: Addison-Wesley. (Original publicado em 1954)

Andersen, R., \& Fetner, T. (2008). Cohort differences in tolerance of homosexuality: Attitudinal change in Canada and the United States, 1981-2000. Public Opinion Quarterly, 72(2), 311-330.

Biernat, M., Vescio, T. K., \& Theno, S. A. (1996). Violating American values: A value congruence approach to understanding outgroup attitudes. Journal of Experimental Social Psychology, 32(4), 387-410.

Bowen, A. M., \& Bourgeois, M. J. (2001). Attitudes toward lesbian, gay and bisexual college students: The contribution of pluralistic ignorance, dynamic social impact, and contact theories. Journal of American College Health, 50(2), 91-96.

Carneiro, N. F. M. S. (2006). Ser, pertencer e participar: Construção da identidade homossexual, redes de apoio e participação comunitária. Tese de Doutorado não publicada, Universidade do Porto, Porto, Portugal.

Carneiro, N. S., \& Menezes, I. (2007). From an oppressed citizenship to affirmative identities: Lesbian and gay political participation in Portugal. Journal of Homosexuality, 53(3), 65-82. 
Comissão Europeia. (2009). Discriminação na EU 2009. Recuperado em 10 maio 2010, de http://ec.europa.eu/ public_opinion/archives/ebs/ebs_317_fact_pt_pt1.pdf

Costa, C. G., Pereira, M., Oliveira, J. M., \& Nogueira, C. (2010). Imagens sociais de pessoas LGBT. In C. Nogueira \& J. M. Oliveira (Orgs.), Estudo sobre a discriminação em função da orientação sexual e da identidade de gênero (pp. 93-147). Lisboa: Comissão para a Cidadania e a Igualdade de Género.

European Commission. (2007). Discrimination in the European Union (Special Eurobarometer 263). Recuperado em 10 maio 2010, de http://ec.europa.eu/ public_opinion/archives/ebs/ebs_263_en.pdf

European Commission. (2008). Discrimination in the European Union: Perceptions, experiences and attitudes (Special Eurobarometer 296). Recuperado em 10 maio 2010, de http://ec.europa.eu/public_opinion/archives/ ebs/ebs_296_en.pdf

Evans, N. J. (2001). The experiences of lesbian, gay and bisexual youths in university communities. In A. R. D’Augelli \& C. J. Patterson (Eds.), Lesbian, gay, and bisexual identities and youth: Psychological perspectives (pp. 181-198). New York: Oxford University Press.

Gaertner, S. L., \& Dovidio, J. F. (Eds.). (2000). Reducing intergroup bias: The common ingroup identity model. Philadelphia, PA: Psychology Press.

Gato, J., Carneiro, N. S., \& Fontaine, A. M. (2011). Contributo para uma revisitação histórica e crítica do preconceito contra as pessoas não heterossexuais. Crítica e Sociedade: Revista de Cultura Politica, 1(1), 139-167.

Glick, P., \& Fiske, S. T. (2001). Ambivalent sexism. In M. P. Zanna (Ed.), Advances in experimental social psychology (Vol. 33, pp. 115-188). San Diego, CA: Academic Press.

Haas, A. P., Eliason, M., Mays, V. M., Mathy, R. M., Cochran, S. D., D’Augelli, A. R., Silverman, M. M., Fisher, P. W., Hughes, T., Rosario, M., et al. (2011). Suicide and suicide risk in lesbian, gay, bisexual, and transgender populations: Review and recommendations. Journal of Homosexuality, 58(1), 10-51.

Hegarty, P. (2006). Where's the sex in sexual prejudice. Lesbian \& Gay Psychology Review, 7(3), 264-275.

Herek, G. M. (1988). Heterosexuals' attitudes toward lesbians and gay men: Correlates and gender differences. The Journal of Sex Research, 25(4), 451-477.

Herek, G. M. (2007). Confronting sexual stigma and prejudice: Theory and practice. Journal of Social Issues, 63(4), 905-925.

Herek, G. M. (2009). Hate crimes and stigma-related experiences among sexual minority adults in the United States: Prevalence estimates from a national probability sample. Journal of Interpersonal Violence, 24(1), 54-74.

Herek, G. M., \& Capitanio, J. P. (1996). Some of my best friends: Intergroup contact, concealable stigma, and heterosexuals' attitudes toward gay men and lesbians. Personality and Social Psychology Bulletin, 22(4), 412-424.
Hudson, W. W., \& Ricketts, W. A. (1980). A strategy for the measurement of homophobia. Journal of Homosexuality, 5(4), 357-372.

Instituto Nacional de Estatística. (2002). Censos 2001: Resultados definitivos: XIV recenseamento geral da população: IV recenseamento geral da habitação. Lisboa: INE.

Iraklis, G. (2010). Predictors of Greek students' attitudes towards lesbians and gay men. Psychology \& Sexuality, 1(2), 170-179.

Kite, M. E., \& Deaux, D. (1986). Attitudes toward homosexuality:Assessment and behavioral consequences. Basic and Applied Social Psychology, 7(2), 137-162.

Kite, M. E., \& Whitley, B. E., Jr. (1996). Sex differences in attitudes toward homosexual persons, behaviors, and civil rights: A meta-analysis. Personality and Social Psychology Bulletin, 22(4), 336-353.

Lacerda, M., Pereira, C., \& Camino, L. (2002). Um estudo sobre as formas de preconceito contra homossexuais na perspectiva das representações sociais. Psicologia: Reflexão e Crítica, 15(1), 165-178.

Lei $N^{\circ}$ 9, de 31 de maio de 2010. (2010, 31 de maio). Permite o casamento civil entre pessoas do mesmo sexo. Diário da República, la Série. Recuperado em 9 junho 2010, de http://dre.pt/pdf1s/2010/05/10500/0185301853.pdf

Lemm, K. M. (2006). Positive associations among interpersonal contact, motivation, and implicit and explicit attitudes toward gay men. Journal of Homosexuality, 51(2), 79-99.

Marinho, C. A., Marques, E. F. M., Almeida, D. R., Menezes, A. R. B., \& Guerra, V. M. (2004). Adaptação da escala de homofobia implícita e explícita ao contexto brasileiro. Paidéia (Ribeirão Preto), 14(29), 371-379. doi: 10.1590/ S0103-863X2004000300012

Marshal, M. P., Dietz, L. J., Friedman, M. S., Stall, R., Smith, H. A., McGinley, J., Thoma, B. C., Murray, P. J., D’Augelli, A. R., \& Brent, D. A. (2011). Suicidality and depression disparities between sexual minority and heterosexual youth: A meta-analytic review. Journal of Adolescent Health, 49(2), 115-123.

Massey, S. G. (2009). Polymorphous prejudice: Liberating the measurement of heterosexuals' attitudes toward lesbians and gay men. Journal of Homosexuality, 56(2), 147-172.

McConahay, J. B. (1986). Modern racism, ambivalence, and the modern racism scale. In J. F. Dovidio \& S. L. Gaertner (Eds.), Prejudice, discrimination, and racism (pp. 91-125). San Diego, CA: Academic Press.

Meertens, R., \& Pettigrew, T. F. (1999). Será o racismo subtil mesmo racismo? In J. Vala (Org.), Novos racismos: Perspectivas comparativas (pp. 11-29). Oeiras, Portugal: Celta.

Moreno, K. N., \& Bodenhausen, G. V. (2001). Intergroup affect and social judgment: Feelings as inadmissible information. Group Processes \& Intergroup Relations, $4(1), 21-29$. 
Morin, S. F. (1977). Heterosexual bias in psychological research on lesbianism and male homosexuality. American Psychologist, 32(8), 629-37.

Morrison, T. G., Kenny, P., \& Harrington, A. (2005). Modern prejudice toward gay men and lesbian women: Assessing the viability of a measure of modern homonegative attitudes within an Irish context. Genetic, Social, and General Psychology Monographs, 131(3), 219-250.

Morrison, M. A., \& Morrison, T. G. (2002). Development and validation of a scale measuring modern prejudice toward gay men and lesbian women. Journal of Homosexuality, 43(2), 15-37.

Nogueira, C., \& Oliveira, J. M. (2010). Um olhar da psicologia feminista crítica sobre os direitos humanos de pessoas LGBT. In C. Nogueira \& J. M. Oliveira (Orgs.), Estudo sobre a discriminação em função da orientação sexual e da identidade de gênero (pp. 9-17). Lisboa: Comissão para a Cidadania e a Igualdade de Gênero.

Park, J. (2001). Development of the heterosexism scale. Tese de Doutorado não publicada, Pennsylvania State University. Recuperado em 15 dezembro 2008, de http:// search.proquest.com/pqdtft/docview/304719844/fulltext PDF/13374B625722BEE9A4E/1?accountid=43623

Pereira, A., Monteiro, M. B., \& Camino, L. (2009). Social norms and prejudice against homosexuals. Spanish Journal of Psychology, 12(2), 576-584.

Pettigrew, T., \& Meertens, R. W. (1995). Subtle and blatant prejudice in Western Europe. European Journal of Social Psychology, 25(1), 57-75.

Quiles del Castillo, M. N., Betancor Rodríguez, V., Rodríguez Torres, R., Rodríguez Pérez, A., \& Coello Martel, E. (2003). La medida de la homofobia manifiesta y sutil. Psicothema, 15(2), 197-204.

Raja, S., \& Stokes, J. P. (1998). Assessing attitudes toward lesbians and gay men: The modern homophobia scale. Journal of Gay, Lesbian, and Bisexual Identity, 3(2), 113-134.

Recusa de dádivas de sangue por homossexuais: Presidente do Instituto Português do Sangue nega discriminação e alega evidências científicas. (2009, 17 julho). Público. Recuperado em 17 julho 2009, de http://ultimahora. publico.clix.pt/noticia.aspx?id=1392233

Sakalli, N. (2002). Pictures of male homosexuals in the heads of Turkish college students: The effect of sex difference and social contact on stereotyping. Journal of Homosexuality, 43(2), 111-126.

Sanches, A. (2009, 2 maio). Tratamentos para alterar orientação sexual não são uma coisa do passado. Público. Recuperado em 20 maio 2009, de http://pt.scribd.com/ shyznogud/d/15376340-Tratamentos-para-alterarorientacao-sexual-nao-sao-uma-coisa-do-passado02052009-Andreia-Sanches-

Swim, J. K., Aikin, K. J., Hall, W. S., \& Hunter, B. A. (1995). Sexism and racism: Old-fashioned and modern prejudices. Journal of Personality and Social Psychology, 68(2), 199-214.
Tougas, F., Brown, R., beaton, A. M., \& Joly, S. (1995). Neosexism: Plus ça change, plus c'est pareil. Personality and Social Psychology Bulletin, 21(8), 842-849.

Wright, L. W., Adams, H. E., \& Bernat, J. (1999). Development and validation of the homophobia scale. Journal of Psychopathology and Behavioral Assessment, 21(4), 337-347.

Jorge Gato é doutorando pelo Programa Doutoral em Psicologia da Faculdade de Psicologia e de Ciências da Educação da Universidade do Porto.

Anne Marie Fontaine é Professora Catedrática da Faculdade de Psicologia e de Ciências da Educação da Universidade do Porto.

Nuno Santos Carneiro é investigador de Pós-doutoramento pelo Centro de Psicologia da Universidade do Porto e investigador visitante do Research Institute for Health and Social Care da Manchester Metropolitan University, bolseiro da Fundação para a Ciência e a Tecnologia.

Recebido: $15 / 01 / 2011$

$1^{a}$ revisão: 19/05/2011

Aceite final: 18/09/2011 